\title{
Responsabilidade civil por erro médico
}

\section{Civil responsibility of the physician for malpractice}

Responsabilidad civil por error médico

Michel Canuto de Sena
Graciele Silva
Gra
Heitor Romero Marques
Paulo Roberto Haidamus de Oliveira Bastos

${ }^{1}$ Graduado em Direito pela Faculdade Mato Grosso do Sul (Facsul). Especialista em Direito Civil e Processo Civil pela Universidade Católica Dom Bosco (UCDB). Mestrando em Farmácia pela Universidade Federal de Mato Grosso do Sul (UFMS). E-mail: canuto.fadir.ufms@gmail.com

${ }^{2}$ Bacharel em Direito pela Unidade de Ensino Superior Dom Bosco (UNDB). Especialista em Direito Civil e Processo Civil pela Universidade Católica Dom Bosco (UCDB). E-mail: gracieleesilva@yahoo.com

${ }^{3}$ Licenciado em Ciências e Pedagogia e Especialista em História e Filosofia da Educação pelas Faculdades Unidas Católicas de Mato Grosso (FUCMT). Mestre em Educação - formação de professores pela UCDB. Doutor em Desarrollo Local y planteamiente territorial pela Universidad Complutense de Madrid (UCM), Espanha. E-mail: heiroma@ucdb.br

${ }^{4}$ Graduação em Farmácia Bioquímica pela Universidade Federal de Mato Grosso do Sul (UFMS). Mestrado e Doutorado em Educação (Currículo) pela Pontifícia Universidade Católica de São Paulo (PUC-SP). Professor titular, pesquisador e membro do Colegiado de Curso do Programa de Pós-Graduação Stricto Sensu Saúde e Desenvolvimento na Região CentroOeste da UFMS. E-mail: phaidamus43@gmail.com 
Resumo: O presente estudo tem como objetivo analisar a responsabilidade civil do médico por danos causados em decorrência de erros cometidos durante atuação profissional ou nas atribuições vinculadas ao exercício da profissão, não importando se os erros resultantes são de atos próprios ou de terceiros interligados com a profissão dele. O trabalho utilizou de dados bibliográficos e documentais fazendo aparato no ordenamento vigente, analisando a responsabilidade penal, ética e civil, tanto na responsabilidade objetiva como subjetiva do médico. Verificou-se a relação jurídica estabelecida entre médico e paciente, dando enfoque nas consequências jurídicas imputadas ao profissional da área médica com a respectiva reparação, na intenção de amenizar a lesão sofrida pela vítima.

Palavras-chave: ética médica; direito a saúde; direitos do paciente; indenização.

Abstract: The present study aims to evaluate the civil responsibility of the physician for damages resulting from medical errors during professional activity or tasks related to the exercise of profession, regardless whether the resulting errors are of own acts or of third parties interconnected with her or his profession. The paper used bibliographical and documental dada, doing analyzing criminal, ethical and civil liability, both in the objective and subjective responsibility of the physician. It was verified the legal relationship established between doctor and patient, focusing on the legal consequences attributed to the doctor with the respective reparation, with intention of mitigating the injury suffered by the victim.

Key words: medical ethics; right to health; patient rights; indemnity.

Resumen: El presente estudio tiene como objetivo analizar la responsabilidad civil del médico por daños causados en virtud de errores cometidos durante la actuación profesional, no importando si los errores son resultantes de actos propios o de terceras personas relacionadas a su profesión. El presente trabajó utilizó datos bibliográficos y documentales haciendo un recorrido en el ordenamiento vigente, analizando la responsabilidad penal, ética y civil, tanto en la responsabilidad objetiva como subjetiva del médico. Se verificó la relación establecida entre el médico y el paciente, dando énfasis en las consecuencias jurídicas imputadas al profesional del área médica con la respectiva reparación, en un intento de amenizar la lesión sufrida por la víctima.

Palabras clave: ética médica; derecho a la salud; derechos del paciente; indemnización. 


\section{CONSIDERAÇÕES INICIAIS}

O presente estudo aborda a responsabilidade civil do médico no exercício de sua profissão, analisando os conceitos e seus pressupostos. A ideia da responsabilidade é decorrente da capacidade do ser humano cometer erros por intermédio de suas condutas trazendo prejuízo a outrem. $O$ direito rege as relações sociais, incumbindo de resolver conflitos quando deste resultar lesão ao bem jurídico tutelado, buscando reparar os danos sofridos pela vítima.

A vida é um bem jurídico tutelado pela Constituição Federal de 1988, à qual a atividade médica está estritamente ligada, por isso a relevância da análise da responsabilidade civil do médico em casos de erros ocorridos no exercício de sua profissão e deste resultar danos fatais e irreparáveis à vida do paciente. Desse modo o profissional está vinculado às regras e sujeito às sanções, quando agir com negligência, imperícia ou imprudência, nos casos de omissão no exercício profissional causar lesões ou morte do paciente, infringindo as regras e a ética profissional.

Diante do exposto, este artigo tem o objetivo de fazer análise sobre a relação de responsabilidade civil envolvendo o binômio médico x paciente, apresentando revisão bibliográfica sobre noções de responsabilização civil, normatizações e sanções aplicadas no contexto, transitando entre material de revisão, discussões e considerações finais pertinentes ao tema.

\section{METODOLOGIA}

Realizou-se revisão narrativa compreensiva envolvendo estudos e pesquisas sobre o fenômeno da responsabilidade civil por erro médico. A análise do conteúdo é considerada a referência bibliográfica em si, consistindo em analisar e realizar hermenêutica de textos presentes em livros, jornais, revistas, periódicos, monografias, dissertações e 
ou teses. Consiste em descrever, interpretar, comparar, identificar as figuras de linguagens, representações coletivas ou individuais e outros dados contidos nas bases referenciais (MARQUES et al., 2014).

As referências apresentadas pela literatura em prol da responsabilidade civil por erro médico, foram coletadas a partir das bases de dados PubMed, SciELO e de outras literaturas encontradas na biblioteca da Universidade Católica Dom Bosco (UCDB) e da Universidade Federal de Mato Grosso do Sul (UFMS).

\section{RESPONSABILIDADE CIVIL}

A responsabilidade civil pressupõe atividade que resulta em dano de direito violado na norma jurídica preexistente. Dependendo da natureza jurídica, a responsabilidade pode ser civil, penal, processual e ética entre outras classificações (TONIN, 2012).

A responsabilização implica no trâmite que indica medidas de reparação a ser compensada a terceiros, a qual pode ser moral e/ou patrimonial. Em razão de culpa exclusiva da vítima, ou seja, quando o indivíduo absorve a causalidade do dano para si, acaba por ser responsável pelo dano por ele mesmo produzido. Dessa forma, será configurada a sua culpa exclusiva, também nos casos de representação (curatela e tutela) ou de imposição legal (SENS, 2009).

Neste sentido, Venosa (2013, p. 2) salienta:

O termo responsabilidade, embora com sentidos próximos e semelhantes, é utilizado para designar várias situações no campo jurídico. A responsabilidade, em sentido amplo, encerra a noção em virtude da qual se atribui a um sujeito o dever de assumir as consequências de um evento ou de uma ação. [...] No vasto campo da responsabilidade civil, o que interessa é saber identificar aquela conduta que reflete na obrigação de indenizar. Nesse âmbito, uma pessoa é responsável quando suscetível de ser sancionada, independentemente de ter cometido pessoalmente um ato antijurídico. Nesse sentido, 
a responsabilidade pode ser direta, se diz respeito ao próprio causador do dano, ou indireta, quando se refere a terceiro, o qual, de uma forma ou de outra, no ordenamento, está ligado ao ofensor.

A responsabilidade civil decorre de ação humana, possui como pressupostos: (I) conduta voluntária, (II) o dano injusto sofrido pela vítima, patrimonial ou extrapatrimonial, (III) a relação de causalidade entre o dano e a ação do agente (IV) o fator de atribuição da responsabilidade pelo dano ao agente, podendo ser de natureza subjetiva ou objetiva (AGUIAR JUNIOR, 2000).

\section{RESPONSABILIDADE CIVIL OBJETIVA E SUBJETIVA}

A responsabilidade civil objetiva, também denominada teoria do risco, estabelece que o sujeito, ao criar danos a terceiros, fica obrigado a repará-los, independentemente se houver culpa. Em tal modalidade não é exigida a análise de culpa, pois o dano é suficiente para se configurar essa responsabilização (LOPES, 2011).

Outro ponto é a responsabilidade civil objetiva estabelecida no Código de Defesa do Consumidor, no artigo 14, § 4ㅇque assim dispõe: "a responsabilidade pessoal dos profissionais liberais será apurada mediante a verificação da culpa". Em se tratando deste estudo, mesmo não havendo relação contratual previamente estabelecida entre paciente e médico, tal conduta não exime o profissional da responder pelos seus atos. Nesse norte, tem-se o entendimento de Rodrigues (2002, p. 10) sobre a teoria da responsabilidade objetiva:

Na responsabilidade objetiva a atitude culposa ou dolosa do agente causador do dano é de menor relevância, pois, desde que exista relação de causalidade entre o dano experimentado pela vítima e o ato do agente, surge o dever de indenizar, quer tenha este último agido ou não culposamente. A teoria do risco é a da responsabilidade objetiva. Segundo essa teoria, aquele 
que, através de sua atividade, cria risco de dano para terceiros deve ser obrigado a repará-lo, ainda que sua atividade e seu comportamento sejam isentos de culpa. Examina-se a situação, e, se for verificada, objetivamente, a relação de causa e efeito entre o comportamento do agente e o dano experimentado pela vítima, esta tem direito de ser indenizada por aquele.

Nesse sentido, o profissional liberal que descumprir regras de segurança no exercício de sua função ficará responsabilizado pelo fato do serviço. Ainda que seja uma obrigação de resultado, cabe ao profissional a comprovação da existência do nexo de causalidade entre a atividade desenvolvida e o dano sofrido pela vítima (GONÇALVES, 2015).

Conforme entendimento de Gonçalves (2015), responsabilidade civil subjetiva trata-se de: "A responsabilidade quando se esteia na ideia de culpa. A prova da culpa do agente passa a ser pressuposto necessário do dano indenizável. Dentro desta concepção, a responsabilidade do causador do dano somente se configura se agiu com dolo ou culpa". Colhe-se o ensinamento de Gonçalves (2015, p. 28) a respeito da responsabilidade subjetiva:

Conforme o fundamento que se dê à responsabilidade, a culpa será ou não considerada elemento da obrigação de reparar o dano. Em face da teoria clássica, a culpa era fundamento da responsabilidade. Essa teoria, também chamada teoria da culpa, ou "subjetiva", pressupõe a culpa como fundamento da responsabilidade civil. Em não havendo culpa, não há responsabilidade. Diz-se, pois, ser "subjetiva" a responsabilidade quando se esteia na ideia de culpa. A prova da culpa do agente passa a ser pressuposto necessário do dano indenizável. Dentro dessa concepção, a responsabilidade do causador do dano somente se configura se agiu com dolo ou culpa.

Na responsabilidade civil subjetiva, far-se-á necessário analisar a culpa do autor, na violação de dever por negligência, imprudência ou imperícia. Tendo em vista que o dano é apurado conforme a reflexão 
da conduta em detrimento do resultado alcançado, tem-se o nexo de causalidade como elemento para apurar a culpa (GONÇALVES, 2015).

\section{EXCLUDENTES DE RESPONSABILIDADE}

As excludentes de responsabilidade civil podem ser compreendidas como circunstâncias que rompem o nexo de causalidade, com o objetivo de alcançar a pretensão, o quantum indenizatório, abarcando elementos e pressupostos da responsabilidade civil (LEITIS, 2011).

As causas de exclusão de responsabilidade civil são: (I) legítima defesa, (II) Estado de necessidade, (III) Fato de terceiro, (IV) Caso fortuito e força maior, (V) Culpa exclusiva da vítima, (VI) Estrito cumprimento do dever legal e (VII) Cláusula de não indenizar.

Na legítima defesa, o agente utiliza de meios necessários para afastar agressão iminente, injusta ou atual, podendo ser em defesa própria ou de terceiros. Se a prática do ato for direcionada contra o agressor, não incorre este em responsabilização civil (TONIN, 2012).

O estado de necessidade tem previsão legal no artigo 188 do Código Civil; consiste na defesa de situação injusta e determinada para proteger direito reconhecido. Isto não isenta o sujeito de atuar dentro dos limites de sua necessidade com intuito de afastar situação de perigo, sendo proibido o excesso. Se o causador do perigo atingir um terceiro, este poderá exigir indenização, como determina os artigos 929 e 930 do Código Civil.

A responsabilidade civil por fato de terceiro determina quais são os sujeitos envolvidos e qual a relação jurídica existente entre eles, tornando juridicamente responsáveis pela prática dos respectivos atos (GANDINI; SALOMÃO, 2003).

O caso fortuito é derivado da vontade alheia e imprevisível às partes e à força maior de acontecimentos naturais. Ambos possuem a mesma característica, a inevitabilidade e imprevisibilidade. Tais 
fatos rompem o nexo causal entre o ato praticado e o dano sofrido (TONIN, 2012).

Conforme o artigo 945 do Código Civil, a culpa exclusiva da vítima concorre com sua contribuição eficaz para ocorrência do dano, excluindo a responsabilidade do evento danoso. Será analisada conforme a gravidade da culpa, em confronto com o causador do dano (ANDRADE, 2014).

No estrito cumprimento do dever legal, o sujeito comete o dano em prol de seu dever, função ou cargo exercido, desde que dentro de suas prerrogativas profissionais, não gerando pretensão indenizatória, por estar ligado diretamente ao exercício regular do direito (ANDRADE, 2014).

A cláusula de não indenizar é regida pelo princípio autonomia da vontade de contratar e pactuar, porém ela não é absoluta, ou seja, segue as limitações da relação contratual, conforme o Código de Defesa do Consumidor no artigo 25, que veda à estipulação de cláusula que impossibilite, exonere ou atenue a obrigação de indenizar. As partes podem estipular as cláusulas contidas no negócio, desde que não sejam abusivas. Depois de realizado o negócio jurídico, a cláusula será nula, se o agente agir com intenção de causar danos por negligência, imprudência e imperícia (CERQUEIRA, 2014).

\section{6 ÉTICA MÉDICA}

Conforme o Código de Ética Médica, a medicina é um ramo responsável pela promoção da saúde das pessoas, de forma individual e coletiva, exercida sem discriminação de nenhuma natureza. O princípio da dignidade da pessoa humana é uma das garantias fundamentais, quando o assunto está relacionado com a profissão médica. Assegura uma vida digna à pessoa, visando à vida coletiva e harmônica, tratando o próximo com a devida igualdade (DINIZ; ZARDO; MACIEL, 2016). 
Nesse sentido conforme Monte (2009, p. 420):

A ética explicita o comportamento a ser adotado no exercício profissional acorde com as concepções morais da sociedade. A ética, basicamente, assenta-se sobre valores morais. Partindo dessa assertiva podemos concluir que os princípios éticos podem ser relativos ou absolutos. Existem muitos equívocos quanto ao relativo e ao absoluto, tanto dos valores como dos princípios.

A não maleficência é um dos princípios básicos da bioética. Em conformidade com ele, o profissional de saúde tem o dever de não causar danos ao paciente. E é considerado como princípio fundamental. Na perspectiva ética, trata-se de um mínimo, que deve ser cumprido e, no caso de descumprimento, coloca o profissional da saúde em situação de prática médica negligente (LOCH, 2002).

Nesse cenário, a ética médica pode ser compreendida como deliberativa, tendo como base a hermenêutica, na responsabilidade e na prudência. Três categorias analíticas são utilizadas: fatos, valores e deveres. O ponto primordial é a experiência moral, constituindo-se como um fato nos ternos fenomenológicos. O agir moral envolve três faculdades da inteligência humana: cognitiva, que são os fatos; emocional que reside nos valores; e a volitiva que são os deveres (CARNEIRO, 2013).

A não maleficência determina as obrigações de não causar danos intencionalmente. No cenário da ética médica, está intimamente ligado com a máxima "Primum non nocere", em outras palavras, não causar dano. No juramento de Hipócrates, estão expressas a obrigação de beneficência e a de não maleficência: "Usarei apenas o tratamento para ajudar o doente de acordo com minha habilidade e com meu julgamento, mas jamais o usarei para lesá-lo ou prejudicá-lo" (BEAUCHAMP; CHILDRESS, 2002).

Outro princípio fundamental no estudo da ética médica é o da autonomia, que consiste na capacidade de a pessoa decidir o que fazer 
ou deixar de fazer. Para exercer a autodeterminação, são fundamentais duas condições: (I) capacidade para agir intencionalmente, o que pressupõe compreensão, razão e deliberação para decidir coerentemente entre as alternativas que Ihe são apresentadas; (II) liberdade, no sentido de estar livre de qualquer influência controladora para esta tomada de posição (LOCH, 2002).

Em regra, no Brasil, todos os profissionais da área médica deveriam ter conhecimento sobre a Constituição Federal de 1988, que dispõe sobre a saúde e respectivamente sobre o Código de Ética Médica, que dispõe sobre os princípios fundamentais "o alvo de toda a atenção do médico é a saúde do ser humano, em benefício da qual deverá agir com o máximo de zelo e o melhor de sua capacidade profissional", proibindo o médico de efetuar qualquer procedimento sem o esclarecimento e o consentimento prévios do paciente ou de seu responsável legal, salvo em iminente perigo de vida (CASTILHO; KALIL, 2005).

Cabe ao Conselho Federal de Medicina apurar e aplicar sanções administrativa de atos praticados por médicos, antes de o conflito ser apreciado judicialmente.

A apuração da responsabilidade ético-disciplinar, ao contrário do processo civil e do processo criminal, se faz em "segredo de justiça" segundo o artigo 38 do Código de Processo ÉticoProfissional [...] "O julgamento disciplinar far-se-á a portas fechadas, sendo permitida somente a presença das partes e seus procuradores, até o encerramento da sessão". Esse segredo é, no entanto, relativo, pois a justiça comum, tanto civil como criminal, pode requisicionar cópias do processo para instruir demandas cíveis ou criminais, utilizando-as como meios de provas. A justiça comum não pode porém apreciar a questão de mérito ético-disciplinar que, legalmente, é da competência exclusiva dos Conselhos de Medicina segundo o artigo $2^{\circ}$ da lei 3.268/57: "O Conselho Federal e os Conselhos Regionais de Medicina são os órgãos supervisores da ética profissional 
em toda a República, e, ao mesmo tempo, julgadores e disciplinadores da classe médica, cabendo-Ihes zelar e trabalhar por todos os meios ao seu alcance, pelo perfeito desempenho ético da medicina e pelo prestígio e bom conceito da profissão e dos que a exerçam legalmente". Os processos éticos estão também sujeitos à prescrição segundo o Código de Processo Ético-Profissional em seu artigo 52: "A punibilidade por falta ética, sujeita a processo ético-profissional, prescreve em 5 anos, contados a partir da data do conhecimento do fato". (UDELSMANN, 2007).

\section{RESPONSABILIDADE PENAL DO MÉDICO}

A responsabilidade penal do médico tem sua origem na ação humana, podendo ser ato comissivo e ou omissivo de um fato típico e antijurídico, com apuração do nexo causal, em detrimento do resultado de um dano, previsto no ordenamento jurídico brasileiro (UDELSMANN, 2007).

A responsabilidade médica não segue padrões, pois o médico goza de autonomia no exercício de sua profissão. Está condicionado às regras legais e às de procedimento que regulamentam a medicina. Para o erro médico gerar a responsabilidade, é necessário comprovação de alguns elementos e circunstâncias, tais como: agente, conduta, resultado e nexo de causalidade (SILVA, 2006).

Na responsabilização penal, existem duas classificações de ilícitos, podendo ser crimes ou contravenções, divididos em culposo ou doloso. No crime culposo, o agente dá causa ao resultado por imprudência, negligência ou imperícia. Já no doloso, a vontade do agente é o fator principal, pois ele quis o resultado ou assumiu o risco de produzi-lo (UDELSMANN, 2007).

O médico poderá ser responsabilizado criminalmente quando no exercício de sua função cometer erro e dele resultar lesão ao sujeito. Caso o médico venha a infringir norma, é direito resguardado do pa- 
ciente exigir sua responsabilização. Nesse sentido, quando o médico causar danos ao paciente, agirá com imprudência. Se não possuir conhecimentos de diagnósticos suficientes, incorre em imperícia. A negligência reside na falta de cautela exigida para com paciente (OLIVEIRA; FONSECA; KOCH, 2011).

Um dos pontos da responsabilidade médica na esfera penal são os crimes próprios, cometidos apenas por médico. Podem ser divididos em: violação de segredo profissional, omissão de doença contagiosa, exercício ilegal da medicina, falsidade de atestado médico, omissão na assistência de recém-nascidos, ou em outras situações que ocorram lesões ao paciente devido à desídia profissional (MARQUARDT; PRATES, 2003).

A violação do segredo profissional visa à proteção da liberdade individual das pessoas que necessitam confidenciar fatos inerentes à intimidade pessoal. Essa indiscrição está tipificada no artigo 154 do Código Penal, sendo tratada como crime de atitude profissional.

A omissão de notificação de doença contagiosa é definida pelo Ministério da Saúde com finalidade de mapear e prevenir doenças. Define a obrigação do médico de respeitar as determinações da vigilância sanitária, e seu descumprimento implica sanção administrativa e penal, conforme disciplina o artigo 268 do Código Penal "Infringir determinação do poder público, destinada a impedir introdução ou propagação de doença contagiosa" (UDELSMANN, 2007).

O exercício ilegal da medicina está tipificado no artigo 282 do Código Penal, dividido em duas condutas distintas: quando a profissão do médico for exercida sem autorização e sem a qualificação técnica. Quando o médico ultrapassar os limites estabelecidos referentes ao exercício de sua profissão, responderá pelo excesso cometido (UDELSMANN, 2007).

Nesse sentido, o atestado médico consiste em documento escrito com presunção de verdade, em função do estado de saúde 
de determinada pessoa, atestando enfermidades do paciente. As declarações contidas em atestado médico recebem fé pública do Estado (LEAL, 2009).

\section{RESPONSABILIDADE CIVIL POR ERRO MÉDICO}

A medicina possui compromisso de meios, mas o erro médico deve ser separado do resultado, quando o médico utilizou todos os recursos com a intenção de obter resultado pretendido. O grande conflito no erro médico reside no fato de as pessoas procurarem a melhoria para saúde e acabarem alcançando um resultado indesejável e maléfico. O resultado danoso é visível aos olhos da sociedade e da classe médica, irreparável e sempre revestido de sofrimento (GOMES; FRANÇA, 1998).

O erro médico é decorrente de ação ou omissão, podendo ser apurado através de três vias principais. No primeiro caso, é a imperícia decorrente de não observação de normas técnicas. O segundo trata-se da imprudência, ou seja, quando o médico, por intermédio de atos comissivos ou omissivos, assume procedimentos de riscos para o paciente sem qualquer tipo de respaldo científico. O terceiro é a negligência, quando ele trata com descaso ou ausenta-se dos deveres e compromissos éticos e profissionais (GIRÃO; ANDRADE, 2015).

Os deveres da conduta médica são fundamentais na construção das virtudes inerentes à qualidade do ato médico. O reflexo dos deveres resulta na contribuição para amenizar ou reduzir ao mínimo a possibilidade de erro médico. Outro ponto relevante é sobre o erro por diagnóstico ou erro de conduta. Alguns doutrinadores defendem o não enquadramento em culpa dessa modalidade, desde que não provocado por negligência. Nesse caso, o médico não realiza procedimentos adequados omitindo novas terapias ao caso do paciente, 
não levam em conta os resultados de diagnóstico, utilizando apenas o "olho clínico" (GOMES; FRANÇA, 1998).

Cabe salientar a diferença entre erro oriundo de acidente imprevisível e de resultado incontornável. O acidente imprevisível é o fato com resultado lesivo, decorrente de caso fortuito ou força maior, possui característica peculiar à incapacidade de ser previsto ou evitado. É conceituado como resultado incontrolável, aquele decorrente de situação incontornável, quando até o momento do resultado, a ciência e a competência do profissional não apontavam soluções para o caso (LIMA, 2012).

O abandono de paciente ocorre quando a pessoa precisa de assistência urgente ou remota e, mesmo assim, o médico deixa de atendê-lo. É uma das formas de negligência mais comum, pois, quando estabelecida a relação contratual entre o paciente e médico, a obrigação de serviço torna-se contínua e garantida (GOMES; FRANÇA, 1998).

A responsabilidade civil do médico decorre da atividade profissional que violar o dever imposto pela lei, costume ou contrato, imputável a título de culpa, que causar dano injusto, patrimonial ou extrapatrimonial. Um dos pressupostos da culpa é extraído dos artigos 186 e 187 do Código Civil, na apuração e caracterização do ato ilícito. Em conformidade com o artigo 927 do referido diploma legal, aquele que, por ato ilícito, causar algum tipo de dano a outrem, fica obrigado a repará-lo, independentemente de culpa (SOARES; SOARES, 2014).

Para o profissional de medicina ser responsabilizado civilmente, é analisada a culpa em sentido estrito, verificando a ocorrência do dano causado ao paciente. O artigo 1538 do Código Civil dispõe que, em caso de ferimento ou de outra ofensa à saúde, o causador ficará obrigado a indenizar o ofendido, com suas despesas e tratamento do inicio ao fim da convalescência, além da possibilidade de fixação da multa correspondente (UDELSMANN, 2007). 
A reparação de danos com fixação de valores de indenização busca prevenir que o ofensor, a título de prática reiterada, prejudique outrem. Essa prevenção se opera por meio da tutela jurisdicional, que busca proteger a ameaça ao direito (DONNINI, 2011).

Configurando erro, o médico poderá ser obrigado a pagar indenização, podendo ser a título de dano moral no caso de morte, dano extrapatrimonial por ofensa à integridade física ou psíquica. Em casos que envolvam a honra da pessoa, é assegurado o dever de sigilo à imagem desta (GONÇALVES, 2015).

Sobre o dano material e moral de erro médico, a jurisprudência dispõe:

DANO MORAL E MATERIAL ERRO MÉDICO Conduta negligente do médico por não realizar exames laboratoriais, bem como, responsabilidade da Instituição Médica de não dispor de profissional apto a realizar exames necessários Procedência - Instituição médica tem responsabilidade contratual objetiva por exercer atividade de meio e restar comprovado dano e nexo causal, diferentemente do médico que tem responsabilidade subjetiva quando comprovada a sua conduta culposa Inversão do ônus da prova é regra de julgamento Reparo nos valores da condenação Indenização por dano material devida somente pelas despesas com tratamento médico, funeral e luto familiar Reparo no valor da indenização por dano moral Recursos Parcialmente Providos. (TJ/SP - APL 000154917.2007.8.26.0126. REL. Ramom Mateo Junior).

Além do erro médico, existem outros fatores que favorecem resultados negativos na relação médico e paciente, como condições inapropriadas de trabalho, ausência de equipe e medicamentos ou terapias adequadas. A maioria dos pacientes não falecem quando estão sendo assistidos no decorrer de tratamentos, mas sim em filas de hospitais, esperando algum tipo de assistência médica (GOMES; FRANÇA, 1998). 


\section{CONSIDERAÇÕES FINAIS}

Frente ao exposto, observa-se que a responsabilidade civil decorre da violação do bem jurídico. Por isso o Código de Defesa do Consumidor protege as relações consumerista, auxilia a parte mais vulnerável da relação. E, nesse aspecto, o artigo 14, parágrafo 4으, do CDC dispõe sobre a responsabilização do profissional liberal que provocar dano a outrem.

A responsabilidade civil determina a obrigação de indenizar, obrigando o causador de danos a repará-los. O médico também poderá ser responsabilizado criminalmente quando infringir norma ou cometer erro e deste resultar lesão ao sujeito, colocando em risco sua vida; esse ato se caracteriza pela intenção do agente.

A saúde não é uma questão de exclusiva responsabilidade médica, mas de toda sociedade. Em contrapartida, o médico não pode abrir mão dos princípios que norteiam sua profissão, devendo sempre buscar a melhor relação possível com o paciente, baseada na transparência, confiança mútua e lealdade.

Nesse sentido, a responsabilidade médica se individualiza pelo elemento culpa advinda dos atos decorrentes do exercício de sua profissão ao agir com negligência, imprudência ou imperícia e ou quando se omitir, e o resultado do feito causar a morte ou lesão ao paciente. Porém a culpa do profissional não pode ser presumida, e sim analisada conforme as regras e os métodos exigidos pela sua profissão em concordância com as legislações vigentes.

\section{REFERÊNCIAS}

AGUIAR JUNIOR, R. R. Responsabilidade civil do médico. 2000. Disponível em: <http://bdjur.stj.jus.br/dspace/handle/2011/555>. Acesso em: 10 nov. 2016. ANDRADE, A. L. D. de. Responsabilidade civil do Estado pela demora da prestação jurisdicional. 2014. Monografia (Especialização em Prática Jurídica) - Universidade Estadual da Paraíba, João Pessoa, PB, 2014. 
BEAUCHAMP, T. L.; CHILDRESS, J. F. Princípios de ética biomédica. São Paulo: Loyola, 2002.

CARNEIRO, H. G. Ética e Bioética no atendimento aos pacientes portadores de HIV/aids no Sistema Único de Saúde. Caderno Iberoamericano de Direito, Brasília, v. 2, n. 2, jul./dez. 2013.

CASTILHO, E. A.; KALIL, J. Ética e pesquisa médica: princípios, diretrizes e regulamentações. Revista da Sociedade Brasileira de Medicina Tropical, Uberaba, MG, v. 38, n. 4, p. 344-347, jul./ago. 2005.

CERQUEIRA, L. O. G. T. Responsabilidade civil do hospital em face do erro médico. 2014. Monografia (Graduação em Direito) - Centro Universitário Antônio Eufrásio de Toledo, Presidente Prudente, SP, 2014.

DINIZ, L. W.; ZARDO, T.; MACIEL, J. C. A dignidade humana e os direitos fundamentais da pessoa com deficiência. Multitemas, Campo Grande, MS, v. 21, n. 49, p. 33-58, jan./jun. 2016.

DONNINI, R. Responsabilidade civil pós-contratual. 3. ed. São Paulo: Saraiva, 2011.

GANDINI, J. A. D.; SALOMÃO D. P. S. Responsabilidade civil do Estado por conduta omissiva. Revista Conselho Federal de Justiça, Brasília, n. 23, p. 4559, out./dez. 2003.

GIRÃO, M. S.; ANDRADE, A. O. Responsabilidade civil por erro médico. 2015. Disponível em: <goo.gl/dU4gKu>. Acesso em: 7 nov. 2016.

GOMES, J. C. M.; FRANÇA, G. V. Erro médico. In: COSTA, S. I. F.; OSELKA, G.; GARRAFA, V. Iniciação à bioética. Brasília: Conselho Federal de Medicina, 1998. p. 243-256.

GONÇALVES, C. R. Responsabilidade civil. 16. ed. São Paulo: Saraiva, 2015.

LEAL, J. J. Exercício da medicina e responsabilidade criminal. Revista Bioética, v. 2, n. 2, p. 1-10, 2009.

LEITIS, D. M. G. A responsabilidade civil dos biomédicos e o ato profissional. Revista Jurídica, Blumenau, SC, v. 15, n. 29, p. 3-14, jan./jul. 2011.

LIMA, F. G. C. Erro médico e responsabilidade civil. Brasília: Conselho Federal de Medicina/Conselho Regional de Medicina do Estado do Piauí, 2012.

LOCH, J. A. Princípios da Bioética. Uma introdução à Bioética. Temas de Pediatria Nestlé, n. 73, p. 12-19, 2002. 
LOPES, S. H. P. O instituto da responsabilidade civil no Código Civil de 2002. Âmbito Jurídico.com.br, 2011. Disponível em: <https://goo.gl/897abN>. Acesso em: 7 nov. 2016.

MARQUARDT, M.; PRATES, D. N. A responsabilidade penal do médico e o processo penal. Jornal Vascular Brasileiro, v. 2, n. 3, p. 241-7, 2003.

MARQUES, H. R.; MANFROI, J.; CASTILHO, M. A.; NOAL, M. L. Metodologia da pesquisa e do trabalho científico. 4. ed., rev. e atual. Campo Grande, MS: UCDB, 2014.

MONTE, F. Q. Ética médica: evolução histórica e conceitos. Revista Bioética, v. 17, n. 3, p. 407-28, 2009.

OLIVEIRA, G. F. T.; FONSECA, M. B.; KOCH, H. A. Responsabilidade civil do radiologista no diagnóstico do câncer de mama através do exame de mamografia. Radiologia Brasileira, São Paulo, v. 44, n. 3, p. 183-7, maio/ jun. 2011.

RODRIGUES, S. Responsabilidade civil. 4. ed. São Paulo: Saraiva, 2002.

SENS, F. M. A reparação do dano moral e a fixação do quantum indenizatório nas relações de consumo. 2009. Monografia (Bacharelado em Direito) Universidade do Vale do Itajaí ( UNIVALE), Itajaí, SC, 2009.

SILVA, A. de. Responsabilidade penal do médico pelos erros cometidos no exercício da função. 2006. Monografia (Bacharelado em Direito) Universidade Federal do Paraná (UFPR), Curitiba, PR, 2006.

SOARES, S. C. A.; SOARES, M. M. Responsabilidade ética e judicial da atuação do médico do trabalho. Âmbito Jurídico.com.br, 2014. Disponível em: <https://goo.gl/hVOeXb>. Acesso em: 16 nov. 2016.

TONIN, D. A. A responsabilidade civil decorrente da execução de um título executivo judicial provisório. 2012. Trabalho de Conclusão de Curso (Bacharelado em Ciências Jurídicas e Sociais) - Universidade de Passo Fundo (UPF), Passo Fundo, RS, 2012. Disponível em: <https://goo.gl/AjyKOK>. Acesso em: 7 nov. 2016.

UDELSMANN, A. Responsabilidade civil, penal e ética dos médicos. Revista Associação Médica Brasileira, São Paulo, v. 48, n. 2, p. 172-82, 2007.

VENOSA, S. S. Direito civil: responsabilidade civil. 13. ed. São Paulo: Atlas, 2013. v. 4. 